\title{
MENGULIK PEMIKIRAN ALFRED N. WHITEHEAD TENTANG KEBUDAYAAN ${ }^{1}$
}

\author{
J. SUDARMINTA*
}

\begin{abstract}
This article attempts to formulate Alfred N. Whitehead's thoughts on culture. Even though he never specifically wrote on culture, his thoughts on it can be gleaned and constructed from his major books. The article will be divided into three parts. First, by borrowing some ideas from David L. Hall's book The Civilization of Experience: A Whiteheadian Theory of Culture, I shall try to formulate what Whitehead means by culture. Second, I shall describe what Hall termes "cultural aims" and "cultural interests" in the perspective of Whitehead's thought. Third, I shall address some important points in Whitehead's critique of modern culture and the alternative he proposed. Finally, I shall point out some major conclusions that can be derived from our study of Whitehead's thoughts on culture.
\end{abstract}

Keywords: Culture, cultural aims, cultural interests, modern culture, civilized society, art, adventure, beauty, truth, peace.

Abstrak: Tulisan ini berupaya merumuskan pemikiran Whitehead tentang kebudayaan. Kendati ia tidak pernah secara khusus menulis tentang kebudayaan, namun pemikirannya dapat diulik dan coba dirumuskan dari berbagai karya pokoknya. Tulisan akan dibagi menjadi tiga bagian. Pertama, dengan memanfaatkan kajian yang pernah dibuat oleh David L. Hall dalam bukunya The Civilization of Experience. A Whiteheadian Theory of Culture, penulis akan merumuskan pengertian kebudayaan menurut Whitehead. Kedua, penulis akan memaparkan apa yang oleh Hall disebut "cita-cita budaya" dan "kepentingan budaya" dalam perpektif pemikiran Whitehead. Ketiga, penulis akan membahas beberapa butir penting dari kritik Whitehead terhadap budaya modern berikut alternatif yang ia tawarkan. Tulisan ini akan ditutup dengan beberapa kesimpulan yang

J. Sudarminta, Program Pasca Sarjana, Sekolah Tinggi Filsafat Driyarkara, Cempaka Putih Indah 100 A, Rawasari, Jakarta 10520. E-mail:jsudarsj@gmail.com.

1 Tulisan ini berawal dari sebuah makalah yang pernah penulis sajikan pada kuliah Extension Course Filsafat di Fakultas Filsafat, Universitas Parahyangan, Bandung, pada tanggal 11 Mei 2012. Makalah tersebut direvisi untuk diterbitkan dalam berkala ilmiah. 
dapat ditarik dari kajian mengenai pemikiran Whitehead tentang kebudayaan.

Kata-kata Kunci: Kebudayaan, cita-cita budaya, kepentingan budaya, budaya modern, masyarakat berkeadaban, seni, petualangan , keindahan, kebenaran, kedamaian.

\section{PENDAHULUAN}

Alfred N. Whitehead tidak pernah menulis buku yang secara khusus menelaah tentang kebudayaan. Namun hal itu tidak berarti bahwa ia tidak memiliki pemikiran tentang kebudayaan. Pemikiran itu memang masih harus diulik atau diselidiki dengan digali dan dirumuskan dari berbagai buku yang ia tulis, misalnya dari mahakaryanya Process and Reality, dan khususnya dari buku-buku yang ia tulis sesudahnya, yakni Function of Reason, Adventures of Ideas, dan Modes of Thought. Pemikirannya tentang kebudayaan sebagai tanggapan kritis terhadap budaya modern yang didominasi oleh alam pikiran yang bersifat dualistik dan paham materialisme ilmiah (scientific materialism) sudah mulai ia kemukakan dalam buku Science and the Modern World yang ditulis pada 1925.

Upaya penulis untuk memaparkan pemikiran Whitehead tentang kebudayaan dalam tulisan ini dibagi dalam tiga bagian. Pertama, dengan memanfaatkan kajian yang pernah dibuat oleh David L. Hall, ${ }^{2}$ penulis ingin mengawali tulisan ini dengan menjelaskan pengertian tentang kebudayaan dalam perspektif pemikiran Whitehead. Kedua, penulis akan mengemukakan apa yang oleh Hall disebut sebagai cita-cita budaya dan kepentingan budaya dalam perspektif pemikiran Whitehead. Ketiga, penulis akan mengemukakan pokok-pokok kritik Whitehead terhadap budaya modern berikut alternatif pemikiran yang ia tawarkan. Seperti akan kita lihat, budaya modern telah didominasi oleh alam pikiran yang bersifat dualistik dan mekanistik. Alam pikiran dualistik memisahkan manusia dari alam, yang mental dari yang fisik, nilai dari fakta, filsafat

2 David L. Hall, The Civilization of Experience: A Whiteheadian Theory of Culture (New York: Fordham University Press, 1973). 
dari sains. Alam pikiran yang bersifat mekanistik ini muncul dari paham yang oleh Whitehead disebut "materialisme ilmiah."

\section{PENGERTIAN TENTANG KEBUDAYAAN DALAM PEMIKIRAN WHITEHEAD}

Sebelum merumuskan pengertian kebudayaan dalam perspektif pemikiran Whitehead, David Hall ${ }^{3}$ meminjam tiga perspektif yang dikemukakan oleh Talcott Parsons ${ }^{4}$ dalam mengkaji masyarakat, yakni "sistem kepribadian," "sistem sosial," dan "sistem budaya." Sistem sosial terkait dengan interaksi antara manusia yang dilihat sebagai aktivitas dengan pola atau struktur tertentu. Sistem kepribadian menyangkut kebutuhan dan kecenderungan individu-individu dalam konteks interaksi tersebut. Sementara itu, sistem budaya menyangkut sistem yang terpola dan terorganisasikan dari simbol-simbol yang menjadi objek sasaran orientasi tindakan serta menjadi komponen yang terbatinkan dalam diri para pelaku tindakan individu dan pola sistem sosial yang terlembagakan. Sistem kepribadian dalam peristilahan Parsons oleh Hall disejajarkan dengan fakta atomik dalam pemikiran Whitehead yang terkait dengan tindakan dan maksud tujuan individu tertentu. Sistem sosial disejajarkan dengan fakta sosial yang terkait dengan kelompok individu, sedangkan sistem budaya disejajarkan dengan bentuk-bentuk pengorganisasian yang menentukan tipe perilaku dan penafsiran makna kegiatan individu serta masyarakat.

Sudah cukup umum diketahui bahwa kata "kebudayaan" tak ada batasan pengertian yang tunggal. Misalnya, pada 1952, Alfred Kroeber dan Clyde Kluckhohn, dalam buku mereka Culture: A Critical Review of Concepts and Definitions, ${ }^{5}$ telah mencatat adanya tidak kurang dari 164 definisi kebudayaan. Kemudian Clifford Geertz dalam bukunya yang klasik The Interpretation of Cultures mendefinisikan kebudayaan sebagai

3 David L. Hall, The Civilization of Experience, p. 61

4 Talcott Parsons, The Social System (Glencoe, Ill.: Open Court, 1929), p. 327.

5 A. L. Kroeber and C. Kluckhohn, Culture: A Critical Review of Concepts and Definitions Cambridge, MA: Harvard University Press), 1952. 
suatu "pola pemaknaan yang terwujud dalam simbol-simbol yang secara historis dialihkan, suatu sistem pemahaman yang diwariskan dan yang terungkap dalam bentuk-bentuk simbolik yang dipakai manusia berkomunikasi, melanggengkan dan mengembangkan pengetahuannya tentang sikap-sikap terhadap kehidupan." ${ }^{6}$ Parsons sendiri, sebagaimana dirujuk oleh Hall, 7 mendefinisikan kebudayaan sebagai sistem simbol yang mencirikan perilaku dan produk tindakan manusia. Sistem budaya terdiri dari apa yang oleh Whitehead disebut "objek-objek abadi" (eternal objects), mirip Idea Platonik, yang pada dirinya sendiri tidak menjadi pelaku aktif dalam proses kegiatan dalam masyarakat, tetapi menjadi dasar pemaknaan kegiatan tersebut. Sistem budaya merupakan bentuk-bentuk abstrak pengorganisasian pemikiran dan tindakan, baik dari individu maupun dari masyarakat, yang menentukan tipe perilaku dan penafsiran makna kegiatan individu serta masyarakat.

Kebudayaan dalam pemikiran Whitehead oleh Hall kemudian didefinisikan sebagai "kompleks cita-cita serta kepentingan yang mendefinisikan dan mengorganisasikan kegiatan manusia dalam masyarakat berikut produk kegiatan tersebut." ${ }^{8}$ Secara abstrak, kebudayaan terdiri dari serangkaian ciri-ciri yang menandai suatu masyarakat maupun bentukbentuk ungkapannya dalam seni, sastra, sistem simbol, sains, teknologi, filsafat, moralitas, agama dan sebagainya yang mengarahkan energi manusia ke arah perwujudan ciri-ciri yang menandai masyarakat tersebut. Suatu masyarakat semakin berkeadaban kalau bentuk-bentuk ungkapan dan kepentingan budaya tersebut menunjang terwujudnya cita-cita peningkatan kualitas atau bobot pengalaman orang-orang yang ada di dalamnya. Pemikiran kebudayaan sebagai kompleks cita-cita serta kepentingan yang mendefinisikan dan memaknai kegiatan manusia dan produk kegiatan tersebut, mengimplikasikan pembicaraan tentang citacita budaya dalam kaitan dengan jenis kegiatan dan objek-objek tertentu.

6 Clifford Geertz, The Interpretation of Cultures (New York: Basic Books, 1973), p. 89.

7 David L. Hall, The Civilization of Experience, p. 72.

8 "Culture is the complex of aims and interests which define and organize human social activity and its products." David L. Hall, The Civilization of Experience, p. 73. 
Seperti halnya Aristoteles, ${ }^{9}$ Whitehead membedakan objek alami dari objek budaya. Objek alami, seperti sebatang rotan di hutan misalnya, melibatkan proses penyebaban internal dan teleologis sebagai aktualisasi potensi yang sudah terkandung di dalamnya. Sementara itu, objek budaya, misalnya sebuah kursi pengantin terbuat dari rotan, merupakan suatu produk penyebaban eksternal, suatu proses artifisial atau buatan manusia. Dalam objek alami, penyebab tujuan (final cause), penyebab bentuk (formal cause), penyebab bahan (material cause) dan penyebab yang mengerjakan (efficient cause) dalam arti tertentu bersifat internal terhadap objek tersebut. Sebaliknya, dalam objek budaya, sebagai sebuah karya seni atau karya cipta manusia, objek alami direduksikan ke status penyebab bahan atau material dari objek karya seni tersebut. Penyebab bentuk (formal cause), penyebab tujuan (final cause) dan penyebab yang mengerjakan (efficient cause) bersifat eksternal terhadap objek tersebut karena bersifat internal dalam diri yang seniman atau pelaku kegiatan yang menghasilkan objek budaya tersebut. Pelaku kegiatan budaya adalah khas manusia, karena manusialah yang dapat memaknai kegiatan hidupnya. Manusia juga mampu memasukkan unsur kebaruan dan melakukan tindakan kreatif yang dimaksudkan guna mengejar suatu intensitas pengalaman subjek, suatu proses tranformasi lingkungan alami seturut maksud cita-cita budaya tertentu.

\section{CITA-CITA DAN KEPENTINGAN BUDAYA DALAM PEMIKIRAN WHITEHEAD}

\section{Cita-Cita Budaya (Cultural Aims)}

Seperti pernah dikemukakan Hall, ${ }^{10}$ konsep kebudayaan Whitehead lebih bersifat teoretis dan normatif daripada praktis dan deskriptif. Kegiatan budaya haruslah diarahkan pada terwujudnya masyarakat yang berkeadaban. Apa yang menjadi cita-cita budaya menurut Whitehead, tercermin dalam pembahasannya tentang ciri-ciri masyarakat yang berkeadaban yang ia rumuskan dalam Bab IV bukunya Adventures of Ideas.

9 Metaphysics 1013A25-1014A25; 1014B16-1015A19.

10 David L. Hall, The Civilization of Experience, pp. 81-111. 
Di situ Whitehead menyatakan bahwa "sebuah masyarakat disebut berkeadaban kalau para warganya berpartisipasi dalam lima kualitas, yakni Kebenaran, Keindahan, Petualangan, Seni dan Kedamaian."11 Kelima kualitas atau nilai yang mencirikan masyarakat yang berkeadaban tersebut dapat disebut sebagai kompleks cita-cita budaya.

Whitehead memahami Kebenaran dalam kaitan dengan peradaban sebagai "penyesuaian Tampakan (Appearance) dengan Kenyataan (Reality)."12 Dengan "Kenyataan" Whitehead memaksudkan sebagai fakta dasariah dari mana proses kreatif ke depan berawal. ${ }^{13}$ "Kenyataan" untuk setiap entitas aktual tertentu adalah dunia aktual masa lalu yang secara kausal terejawantah atau terobjektivasikan dalam entitas aktual tersebut. Dengan "Tampakan," Whitehead memaksudkan suatu dunia aktual yang terbentuk sebagai hasil aktivitas kreatif subjek yang autonom. Di dalamnya terjadi perpaduan antara yang mental dengan yang fisik, yang ideal dan yang aktual, yang transenden dan yang imanen. "Tampakan" adalah dampak dari aktivitas kutub mental entitas aktual yang mengubah bentuk kualitas dan koordinasi duna fisik. Kebenaran merupakan kualitas yang melekat pada Tampakan. Kenyataan sendiri tidak dapat benar atau salah.

Bagi Whitehead, yang lebih mengutamakan pengalaman dengan segala kekayaan dan kompleksitasnya dari pada pengetahuan, "Keindahan lebih luas dan lebih mendasar dibandingkan Kebenaran."14 Whitehead membedakan tiga tipe relasi Kebenaran. Pertama, relasi kebenaran yang lugas (blunt truth), misalnya, seekor banteng bereaksi menyerang ketika melihat kain warna merah yang dikibarkan seorang matador. Kebenaran warna merah kain terungkap dari reaksi menyerang dari banteng yang melihatnya. Kedua, relasi kebenaran indrawi sesuai dengan cerapan panca indra, misalnya, ketika ada burung berkicau di pohon samping rumah dan pendengaran telinga kita normal, maka kebenaran bahwa burung

11 Alfred N. Whitehead, Adventures of Ideas (New York: A Free Press Paperback, 1933), p. 285.

12 Alfred N. Whitehead, Adventures of Ideas, p. 241.

13 Alfred N. Whitehead, Adventures of Ideas, p. 210.

14 Alfred N. Whitehead, Adventures of Ideas, p. 265. 
berkicau di pohon samping rumah terungkap dari kenyataan kita mendengar kicauan burung itu. Ketiga, relasi kebenaran simbolik yang khas pada pengalaman manusia yang sadar. Kata-kata, entah diucapkan atau ditulis, sebagai simbol dan maknanya, merupakan contoh relasi kebenaran simbolik. Simbol-simbol tertentu, seperti kata-kata yang dipakai dalam puisi atau pun drama, tidak hanya menyampaikan makna objektif, tetapi juga bentuk subjektif (subjective form) penerimaannya. Relasi kebenaran simbolik berlaku juga untuk musik, pakaian upacara atau perayaan, bebauan dalam ritus peribadatan, tindak seremonial. Tipe relasi kebenaran yang relevan untuk pemikiran Whitehead tentang kebudayaan adalah relasi kebenaran simbolik.

Whitehead menolak penafsiran intelektualistik dan teoretik dari status proposisi linguistik seperti kaum Positivis Logis, misalnya, yang menilai status proposisi hanya dari nilai kebenarannya atau dari apakah proposisi itu dapat ditegaskan benar-salahnya, entah berdasarkan penalaran logis atau berdasarkan pengamatan indrawi. Dalam perspektif metafisika pengalaman yang dikembangkan Whitehead, di mana pengalaman estetik menjadi model utama penafsiran, proposisi adalah undangan yang menarik untuk dirasakan (a lure for feeling). Dalam pengalaman estetik, fokus perhatiannya adalah pada kedalaman dan intensitas rasa dalam diri subjek yang mengalami. Maksud dan tujuan yang memandu proses perwujudan diri yang ia sebut concrescence adalah perwujudan Keindahan, yakni "penyesuaian timbal balik dari beberapa faktor dalam peristiwa pengalaman."15 Tempat kedudukan Keindahan adalah pada bentuk tanggapan subjek atas apa yang dialami. Di dalamnya unsur nilai dan kebermaknaan (importance) bersifat hakiki.

Whitehead mendefinisikan Seni (Art) sebagai "penyesuaian yang disengaja dari Tampakan terhadap Kenyataan."16 Ia juga menyebutnya sebagai "the education of nature."17 Karya seni mesti didasarkan atas dan berakar dalam kenyataan yang ada. Karena pengalaman estetik bagi

15 Alfred N. Whitehead, Adventures of Ideas, p. 252.

16 Alfred N. Whitehead, Adventures of Ideas, p. 267.

17 Alfred N. Whitehead, Adventures of Ideas, p. 271. 
Whitehead merupakan model utama bagi penafsiran pengalaman pada umumnya, maka tak mengherankan bahwa definisi Seni yang diberikan Whitehead mirip dengan karakterisasi umum proses pengalaman. Sebagaimana proses pengalaman memiliki suatu tujuan, demikian juga Seni. Tujuan Seni bagi Whitehead adalah Kebenaran dan Keindahan. Kendati suatu taraf kesuksesan tertentu sudah dicapai ketika salah satu dari keduanya, entah Kebenaran entah Keindahan sudah ada, penyempurnaan Seni mengandaikan pencapaian Keindahan yang Sebenarnya. Kualitas Keindahan yang Sebenarnya tercapai apabila dalam karya Seni terjadi "perajutan kemutlakan dengan kenisbian."18 Kemutlakan datang dari keunikan dan individualitas dari faktor-faktor pembentukannya yang tak dapat tereduksi lagi; masing-masing merupakan suatu fakta tegar (stubborn fact) yang tidak dapat dielakkan oleh subjek yang mempersepsikannya. Kenisbian muncul dari fakta bahwa semua faktor yang menjadi unsur-unsur pembentuk itu menyerahkan keunikan individualnya sebagai bagian dari penciptaan keselarasan keseluruhan. Kualitas Kebenaran tercapai manakala unsur kemutlakan terjaga. Kualitas Keindahan diwujudkan manakala unsur kenisbian menjadi keselarasan dalam pembentukan bagian-bagiannya menjadi suatu keseluruhan yang terpadu menjadi satu.

Konsep Seni, dalam pemikiran Whitehead, merupakan konsep kunci dalam memahami teorinya tentang peradaban. Karakterisasi karya Seni sebagai perajutan kemutlakan dengan kenisbian merupakan alat analisis yang digunakan Whitehead, bukan hanya untuk menggambarkan pengalaman pada umumnya, tetapi juga untuk menganalisis kegiatan sosial yang berkeadaban. Hal itu nampak dari kutipan berikut:

One of the most general philosophic notions to be used in the analysis of civilized activities is to consider the effect on social life due to the variations of emphasis between Individual Absoluteness and Individual Relativity. Here 'absoluteness' means the notion of release from essential dependence on other members of the community in respect to modes of activity, while relativity means the converge fact of essential relatedness. ${ }^{19}$

18 Alfred N. Whitehead, Adventures of Ideas, p. 264.

19 Alfred N. Whitehead, Adventures of Ideas, p. 43. 
Konteks kutipan di atas adalah pembahasan Whitehead tentang aspek kebebasan dalam sejarah peradaban umat manusia. Dalam masyarakat yang berkeadaban, kemutlakan individual, sebagai tuntutan kebebasan, selalu dipadukan dengan kenisbian individual. Peradaban tak mungkin ada dan tetap ada tanpa penyesuaian timbal balik antara pengaturan yang menuntut disiplin warga masyarakat dan penghormatan terhadap kebebasan individu. Seperti ditegaskan oleh Whitehead: "A mere unqualified demand for liberty is the issue of shallow philosophy, equally noxious with the antithetical cry for mere conformation to standard pattern." 20

Selain Seni, bagi Whitehead, Petualangan (Adventure) juga merupakan unsur penting dalam peradaban. Pemertahanan secara statis apa yang dipandang sempurna pun tidak dapat bertahan karena "bahkan kesempurnaan pun akan tidak tahan terhadap kejenuhan pengulangan terusmenerus." ${ }^{21}$ Cepat atau lambat pengulangan tipe yang dianggap sempurna itu akan mencapai titik jenuh dan menjadi basi. "Tidak ada satu generasi pun yang dapat hanya mereproduksi nenek moyangnya." ${ }^{22}$ Salah satu contoh kejenuhan akibat pengulangan tipe yang sama yang dianggap sempura dalam sejarah perkembangan peradaban yang disebut oleh Whitehead adalah pengulangan capaian budaya Yunani Kuno yang penuh gairah kehidupan dalam karya seninya menjadi pengulangan yang pudar dalam budaya Hellenistik. Ada kelembutan rasa, tetapi tanpa kekuatan petualangan. ${ }^{23}$ Tanpa memberi ruang bagi Petualangan sebagai medan ekspresi kebebasan individu para warganya, sebuah masyarakat akan menjadi beku, mati rasa dan kehilangan gairah hidupnya. Masyarakat itu kehilangan vitalitas semangat kemudaannya.

Pentingnya Petualangan bagi pengembangan masyarakat yang berkeadaban dalam pandangan Whitehead berakar dalam ciri hakiki kenyataan sendiri. Tiga prinsip metafisis yang mendasarinya menurutnya adalah prinsip proses, prinsip keterbatasan dan prinsip individualitas. Selaras

20 Alfred N. Whitehead, Adventures of Ideas, p. 56.

21 Alfred N. Whitehead, Adventures of Ideas, p. 258.

22. Alfred N. Whitehead, Science and the Modern World (New York: Free Press, 1967), p. 188.

23 Alfred N. Whitehead, Adventures of Ideas, pp. 257-258. 
dengan prinsip proses, kebudayaan perlu dimengerti secara dinamis sebagai kata kerja dan bukan kata benda. Tidak ada puncak budaya yang tak mungkin berubah lagi. Prinsip keterbatasan juga mendasari pentingnya Petualangan. Setiap capaian budaya, setinggi apa pun, selalu memiliki keterbatasan. Alasannya adalah dalam capaian itu selalu saja ada unsur yang belum atau tidak terwujudkan. Setiap kegiatan yang bermakna selalu memuat unsur pilihan, dan dalam setiap pilihan tidak hanya ada unsur yang dimasukkan (inclusion) tetapi juga ada unsur yang tidak dimasukkan (exclusion) karena dalam perspektif kegiatan yang bersangkutan menjadi tidak relevan. Selalu saja ada "yang lain" yang sesungguhnya mungkin saja masuk, tetapi tidak masuk. "There are always 'others,' which might have been and are not." ${ }^{24}$ Pembayangan alternatif yang mungkin adalah kegiatan apa yang oleh Whitehead disebut "conceptual feelings" yang mendasari Petualangan. Petualangan sebagai kualitas yang mesti ada dalam masyarakat yang berkeadaban erat terkait dengan kegiatan merasarasakan secara konseptual kemungkinan mewujudkan gagasan-gagasan baru (conceptual entertainment of new ideas). Prinsip metafisis yang ketiga yakni prinsip individualitas juga menggarisbawahi pentingnya Petualangan dalam masyarakat yang berkeadaban karena prinsip individualitas menekankan kebebasan individu. Masyarakat yang berkeadaban memang mencita-citakan terwujudnya Kedamaian dan Keselarasan sosial. Akan tetapi, cita-cita dan upaya perwujudannya tidak boleh mengorbankan kebebasan individu yang menjadi para warganya. Untuk itu, ruang bagi Petualangan Gagasan (Adventures of Ideas) guna mewujudkan alternaif yang mungkin dan membawa pembaruan, harus tetap disediakan.

Berbicara tentang Keselarasan ke arah mana proses peradaban ditujukan membawa kita ke pembahasan tentang unsur kualitas atau nilai terakhir dalam kompleks cita-cita budaya dalam pemikiran Whitehead yang perlu diwujudkan yakni Kedamaian (Peace). Arti kata "perdamaian" dalam penggunaan sehari-hari, kendati bukannya tanpa kaitan, masih kurang memadai untuk merepresentasikan apa yang dimaksudkan oleh Whitehead. Dengan Peace sebagai salah satu nilai yang 24 Alfred N. Whitehead, Adventures of Ideas, p. 276. 
harus ada dan menandai masyarakat yang berkeadaban, ia memaksudkan sebagai Keselarasan dari semua Keselarasan yang mengikat bersama empat nilai atau kualitas masyarakat berkeadaban yang lain, yakni Kebenaran, Keindahan, Seni, dan Petualangan. Pengikatannya sedemikian rupa sehingga menghindarkan proses pengembangan budaya yang menuju masyarakat berkeadaban itu dari egoisme yang penuh keresahan atau konflik tanpa henti karena saling berebut kemenangan bagi diri sendiri.

\section{Kepentingan Budaya (Cultural Interests)}

Mengikuti pandangan Hall, ${ }^{25}$ dengan "kepentingan budaya," dimaksudkan cara-cara lewat mana manusia menyalurkan energi mereka guna mewujudkan cita-cita budaya yang mendefinisikan masyarakatnya dan mencapai tujuan masyarakat yang berkeadaban. Salah satu bentuk kepentingan budaya yang dapat mewujudkan cita-cita budaya guna mencapai tujuan masyarakat yang berkeadaban adalah sains. Kenyataan bahwa sains tidak disebut sebagai salah satu kualitas atau nilai yang menurut Whitehead menandai masyarakat yang berkeadaban, telah menyebabkan orang, seperti A. H. Johnson ${ }^{26}$ misalnya, menarik kesimpulan bahwa bagi Whitehead, sains bukanlah hal yang niscaya diperlukan dalam masyarakat yang berkeadaban. Penulis setuju dengan Hall ${ }^{27}$ bahwa tafsiran dan penarikan kesimpulan Johnson itu tidak tepat. Sains tidak disebut oleh Whitehead sebagai salah dari lima nilai yang menandai masyarakat yang berkeadaban, bukan karena sains tidak penting untuk peradaban, tetapi karena sains bukanlah nilai yang menandai masyarakat yang berkeadaban. Sains adalah salah satu bentuk kepentingan budaya yang dapat menunjang atau pun menghalangi terwujudnya lima nilai yang menandai masyarakat yang berkeadaban yang sudah dijelaskan di atas, tergantung dari bagaimana sains itu dipahami dan dijalankan. Kendati Whitehead bersikap kritis terhadap sains, pada umumnya ia menghargai peran penting dan sumbangan sains bagi peradaban umat

25 David L. Hall, The Civilization of Experience, p. 112.

26 A. H. Johnson, Whitehead's Theory of Reality (Boston: Beacon Press, 1952), pp. 10-11.

27 David L. Hall, The Civilization of Experience, pp. 212-213. 
manusia. Fungsi sains bagi proses peradaban kalau ditempatkan dalam konteks kelima ciri yang menandai masyarakat yang berkeadaban di atas secara khusus menunjang nilai Kebenaran dan Petualangan.

Benarlah bahwa bagi Whitehead kebenaran yang disajikan oleh sains tentang kenyataan yang ada bukanlah kebenaran yang mutlak dan tak berubah. Kebenaran pengetahuan yang dihasilkan sains selalu bersifat sementara, yakni benar selama belum ada bukti lain yang menggugurkannya. Sains secara metodis selalu melibatkan abstraksi dari fakta yang kongkret. Walaupun demikian, bagi Whitehead, sains juga mengungkapkan suatu yang objektif tentang apa yang ada dalam alam. Ia memahami hukum alam sebagai suatu yang imanen dalam alam. Artinya, "tatanan alam mengungkapkan ciri-ciri hal yang real yang secara bersamaan membentuk eksistensi yang perlu ditemukan dalam alam." ${ }^{28}$ Sesuai dengan ajaran ini, para pelaku sains mengupayakan penjelasan tentang gejala-gejala yang menyingkapkan potensi-potensi yang terkandung dalam alam dan bukan sekadar memaparkan apa yang dapat diamati dan diukur.

Selain menyumbang bagi perwujudan nilai Kebenaran, dalam perspektif nilai-nilai yang menandai masyarakat yang berkeadaban, sains juga menunjang nilai Petualangan. Keterbatasan kebenaran sains disebabkan oleh keterbatasan konsep-konsepnya untuk menjelaskan realitas yang terus berubah, mengundang perlunya petualangan gagasan yang membawa terobosan baru. Pengembangan sains ke arah perwujudan masyarakat yang berkeadaban mengandaikan bahwa para pelaku sains selalu penuh rasa ingin tahu dan berani melakukan petualangan gagasan baru. Ketika berbicara tentang prasyarat kemajuan sosial, Whitehead secara khusus menekankan peran sains dalam mempromosikan petualangan gagasan. ${ }^{29}$

28 Alfred N. Whitehead, Adventures of Ideas, pp. 111-112.

29 Hal itu nampak dari kutipan berikut: "Modern science has imposed on humanity the necessity for wandering. Its progressive thought and its progressive technology make the transition into uncharted seas of adventure. The very benefit of wandering is that it is dangerous and needs skill to avert evils. We must expect, therefore, that the future will disclose dangers. It is the business of the future to be dangerous; and it is among the merits of science that it equips the future for its duties." Alfred N. Whitehead, Science and the Modern World (New York: The Free Press, 1967), p. 207. 
Selain sains dan penerapannya dalam teknologi, kepentingan budaya yang lain yang menunjang terwujudnya masyarakat yang berkeadaban yang banyak dibahas oleh Whitehead adalah agama. Terkait dengan lima ciri yang menandai masyarakat yang berkeadaban yang telah dibahas di atas, bagi Whitehead, agama amat berperan untuk pengembangan semangat Petualangan dan menumbuhkan rasa Damai. Whitehead juga menyadari bahwa dalam praktik, agama alih-alih mengembangkan semangat bertualang, malah sering menjadi benteng konservatisme. Padahal kecenderungan ke arah konservatisme itulah sebenarnya yang telah ikut menyebabkan semakin pudarnya pengaruh agama terhadap peradaban Eropa. Ia berpendapat bahwa "agama tidak akan dapat memperoleh kembali kekuatan lamanya sampai ia mampu menghadapi perubahan dalam semangat yang sama dengan sains." 30 Walaupun prinsip dasar agama mungkin abadi, ungkapannya dalam situasi kongkret dan sepanjang sejarahnya menuntut modifikasi terus menerus. Terkait tuntutan untuk modifikasi terus menerus ungkapan keagamaan ini, Whitehead berpendapat bahwa "agama-agama melakukan bunuh diri apabila mereka menimba inspirasi dasarnya dari dogma mereka." 31 Menurut dia, karena masalah nyata dan praktis agama hanya dapat dipelajari dalam sekolah pengalaman sepanjang sejarahnya, "inspirasi dasar agama terletak dalam sejarah agama." ${ }^{32}$ Ini tidak berarti bahwa Whitehead mengabaikan pentingnya dogma bagi hidup beragama. Dogma sebagai rumusan sistematik ajaran agama, merupakan unsur intelektual agama yang menjaminnya dari pereduksian ke hal-hal melulu bersifat emosional. Agama memerlukan teologi sistematis sebagai basis intelektualnya. ${ }^{33}$

Konsep peradaban Whitehead dapat dikatakan sebagai konsep yang teistik, dalam arti konsep itu dibangun atas dasar pengertian Tuhan sebagai unsur yang mendasari dan menjadi puncak dari proses peradaban. Ciri

30 Alfred N. Whitehead, Science and the Modern World, p. 189.

31 Alfred N. Whitehead, Religion in the Making (New York: New American Library, 1974), p. 138.

32 Alfred N. Whitehead, Religion in the Making, p. 138.

33 Bdk. Alfred N. Whitehead, Adventures of Ideas, pp. 161-162. 
teistik dari konsep peradaban Whitehead ini menjadi lebih jelas lagi ketika kita menyadari bagaimana rasa Damai yang merupakan unsur amat penting dalam kualitas yang menandai masyarakat yang berkeadaban, erat sekali terkait dengan peran agama. Rasa Damai akan muncul dari kepercayaan bahwa Tuhan adalah "ukuran konsistensi estetis dunia."34 Kendati unsur kehilangan dan kematian merupakan bagian yang tak terelakkan dalam proses kemajuan kreatif dunia, berkat kehadiran imanen Tuhan dalam dunia, ada suatu konsistensi dalam proses tersebut. Dalam gambaran kosmologis Whitehead, kodrat primordial Tuhan (the primordial nature of God) adalah perwujudan konseptual yang komplet dari semua objek abadi sebagai ranah kemungkinan murni. Visi keseluruhan kodrat primordial Tuhan mengkoordinasikan dan menyesuaikan setiap nilai yang mungkin diwujudkan. Dipadukan dengan apa yang oleh Whitehead disebut sebagai kodrat akhir Tuhan (the consequent nature of God), di mana setiap perwujudan fisik dari visi primordial dalam dunia aktual diobjektivasikan dalam Tuhan yang "tidak akan kehilangan apa pun yang masih dapat diselamatkan," 35 setiap individu dihargai baik dalam kemungkinan idealnya mapun dalam perwujudan aktualnya. Setiap individu itu bernilai, baik dalam dirinya sendiri, bagi yang lain maupun bagi keseluruhan. Kesadaran akan kebenaran ini, sebagai kontras antara fakta yang terus berlalu dan adanya unsur yang tetap dalam semesta alam, memberi rasa Damai. Bagi Whitehead, kesadaran macam itu bersifat religius.

Pentingnya agama sebagai salah satu kepentingan budaya bagi peradaban, terletak dalam perannya dalam menyediakan bagi manusia pola-pola kepercayaan dan perasaan yang memberi jaminan bahwa pencarian yang tak kunjung henti di dunia ini guna mencapai tujuan akhir kehidupan tak pernah sia-sia. Agama memberikan jawaban positif pada permasalahan apakah di balik kegagalan dan kematian ada keabadian. Seperti dikatakan oleh Whitehead sendiri: "Religion is the direct apprehension that, beyond such happiness and such pleasure, there remains the

34 Alfred N. Whitehead, Religion, p. 96.

35 Alfred N. Whitehead, Process and Reality, p. 346. 
function of what is actual and passing, that it contributes its quality as an immortal fact to the order which inform the world." ${ }^{36}$ Intuisi keagamaan yang membawa ke kepercayaan pada Tuhan sebagai penyelamat dari tragika kehidupan yang terus berubah di dunia ini merupakan faktor yang amat penting bagi kehidupan yang berkeadaban. Tanpa itu, sulit diperoleh rasa Damai di dalam hati, dan kehidupan manusia di bumi ini hanya terasa sebagai serpihan kegembiraan sesaat di tengah samudra duka dan derita.

Terkait dengan peran moralitas sebagai suatu kepentingan budaya dalam proses peradaban di samping sains dan agama, Whitehead memahami etika sebagai semacam estetika. "Tatanan moral hanya aspek tertentu dari estetika." ${ }^{37}$ Dalam keduanya, keselarasan dan intensitas pengalaman dicapai lewat pencapaian kontras di bawah pola identitas tertentu. Satu-satunya perbedaan di antara keduanya adalah bahwa pengalaman estetik terkait dengan perspektif apa yang langsung dirasakan sekarang, sedangkan pengalaman moral terkait dengan penentuan relevansinya bagi masa depan. Tetapi karena keindahan pribadi yang terbentuk dalam proses perwujudan diri dalam relasi dan interaksinya dengan lingkungan sekitarnya, pembentukan diri itu sekaligus akan menentukan kualitas dirinya di hadapan orang-orang lain dan bagi keseluruhan. Keputusan transenden yang mendasari tanggung jawab moral dan yang akan menentukan kualitas pribadi pelakunya bagi diri sendiri, bagi orang lain dan bagi keseluruhan, sekaligus merupakan keputusan imanen dalam diri pribadi pelaku tindakan tersebut. "Pribadi yang lemah juga akan membawa dampak pengaruh yang lemah pula." ${ }^{38}$

Selain sains, agama dan moralitas, bagi Whitehead, filsafat juga merupakan suatu bentuk kepentingan budaya yang punya peran penting dalam mewujudkan cita-cita budaya menuju masyarakat yang berkeadaban. Dalam pandangan Whitehead, sains dan filsafat adalah dua aspek dari satu upaya besar budi manusia dengan tugas kerjasama untuk

36 Alfred N. Whitehead, Religion, pp. 77-78.

37 Alfred N. Whitehead, Religion, p. 101.

38 Alfred N. Whitehead, Adventures of Ideas, p. 292. 
mengangkat kemanusiaan di atas tingkat umum kehidupan binatang. ${ }^{39}$ Dengan kata lain, sains dan filsafat punya peran budaya yang penting. Peran yang berguna dari filsafat adalah menunjang sistematisasi umum dari pemikiran yang berkeadaban. Dalam melaksanakan fungsi itu, dan agar sistematisasi umum itu dapat menemukan penerapan konkret, filsafat perlu berangkat dari generalisasi faktor-faktor partikular yang ditarik dari topik-topik yang penting bagi manusia. Ini berarti sains menyediakan titik tolak dan sarana penerapan refleksi filsafat. Menurut Whitehead, agar efektif dalam melaksanakan perannya, filsafat mesti menjalin relasi erat dengan sains dan agama. Terkait dengan hubungan antara sains dan agama, Whitehead memandang keduanya sebagai dua bentuk daya kekuatan umum yang amat kuat mempengaruhi hidup manusia. Maka tak mengherankan kalau ia menegaskan bahwa masa depan sejarah umat manusia akan tergantung dari keputusan yang kita ambil dalam menghubungkan keduanya. ${ }^{40}$ Dalam pandangan Whitehead, filsafat juga punya tugas untuk melakukan kritik terhadap berbagai bentuk abstraksi. Karena kita tidak dapat berpikir tanpa abstraksi, kita harus senantiasa waspada untuk secara kritis merevisi bentuk-bentuk abstraksi kita. ${ }^{41}$ Filsafat bertugas untuk mendapatkan kembali totalitas kenyataan yang cenderung dikaburkan oleh seleksi ilmu-ilmu. "Philosophy is an attitude of mind towards doctrines ignorantly entertained...[It] is a resolute attempt to enlarge the understanding of the scope of application of every notion which enters into our current thought." 42

\section{KRITIK WHITEHEAD TERHADAP BUDAYA MODERN DAN ALTERNATIF YANG DITAWARKAN}

\section{KritiK Terhadap Budaya Modern}

Yang dimaksud dengan budaya modern yang dikritik oleh Whitehead adalah budaya yang ditandai oleh apa yang ia sebut pembelahan alam

39 Alfred N. Whitehead, Adventures of Ideas, p. 140.

40 "When we consider what religion is for mankind, and what science is, it is no exaggeration to say that the future course of history depends upon the decision of this generation as to the relations between them." Alfred N. Whitehead, Science and the Modern World, p. 181.

41 Alfred N. Whitehead, Science and the Modern World, p. 59.

42 Alfred N. Whitehead, Modes of Thought (New York: The Free Press, 1968), p. 171. 
(the bifurcation of nature) yang memisahkan manusia dari alam, yang mental dari yang fisik, filsafat dari sains, nilai dari fakta, subjek dari objek, yang ilahi dari yang duniawi. Dalam sejarah filsafat pandangan dunia yang bersifat dualistik itu berawal dari Descartes yang meyakini bahwa manusia terdiri dari dua substansi yang tidak hanya dapat dibedakan tetapi juga dapat dipisahkan satu sama lain, yakni jiwa dan badan, pikiran dan materi. Jiwa atau pikiran ia sebut "res cogitans" (sesuatu yang kegiatannya berpikir) dan badan atau materi sebagai "res extensa" (sesuatu yang terbentang). Dualisme Cartesian praktis terus menghantui seluruh alam pikir modern sampai dengan I. Kant. Budaya modern juga budaya yang didominasi oleh pandangan kosmologis yang ia sebut "materialisme ilmiah" (scientific materialism). Whitehead mendefinisikan "materialisme ilmiah" sebagai pandangan kosmologis yang berpendapat bahwa dunia ini terbuat dari konfigurasi potongan-potongan materi yang terhubung satu sama lain melulu secara eksternal dan yang pada dirinya sendiri tanpa arti, tanpa nilai dan tanpa maksud dan tujuan. Dunia adalah materi, alam yang mati, statis, lembam dan sepenuhnya dapat dijelaskan secara mekanis. Maka materialisme ilmiah identik dengan mekanisme materialistik. Dalam kosmologi modern realitas secara keseluruhan dipahami sebagai ibarat mesin.

Menurut Whithead, yang mendasari materialisme ilmiah adalah sintesis fisika pertama yang disediakan oleh Galileo dan Newton. ${ }^{43}$ Sintesis fisika pertama ini menekankan uniformitas alam, pentingnya matematika dalam fisika dan pembedaan antara kualitas primer dan kualitas sekunder. Sintesis ini sesungguhnya merupakan capaian intelektual yang pantas dicatat dalam sejarah karena berhasil memadukan antara tilikan yang mendalam tentang fakta alam dengan kemampuan merumuskan generalisasi abstrak yang efektif. Dari sudut pandang pragmatis, materialisme ilmiah telah banyak berguna dan bersama dengan keyakinan bahwa pengetahuan itu kekuatan untuk menguasai alam telah mendorong perkembangan dan timbulnya revolusi di bidang sains dan teknologi.

43 Alfred N. Whitehead, "The First Physical Synthesis," in Interpretation of Science, Selected Essays, ed. A. H. Johnson (New York: The Bobbs-Merril Company, Inc., 1961), Chapter 1 , pp. $237-253$. 
Kenyataan bahwa paradigma fisika Newton berhasil menguasai komunitas para fisikawan selama hampir tiga setengah abad menunjukkan bahwa ada suatu yang memang layak diperhatikan di dalam paradigma tersebut. Namun perlu diingat bahwa kesuksesan paham materialisme ilmiah secara pragmatis dan teknologis adalah karena secara metodis merupakan abstraksi dari realitas kongkret yang lebih kompleks.

Bagi Whitehead, materialisme ilmiah melakukan kekeliruan yang ia sebut "the fallacy of misplaced concreteness" yakni kekeliruan menganggap sebagai suatu yang kongkret apa sesungguhnya merupakan abstraksi. Beberapa contoh kekeliruan yang dikritik Whitehead adalah apa yang ia sebut "simple location," metafisika substansi, dan paham sensasionalisme. "Simple location" adalah anggapan bahwa benda-benda yang ada di dunia ini terletak begitu saja mengambil tempat tertentu, tetap dan tak berubah, serta melulu secara eksternal berelasi satu sama lain. Padahal realitas terdiri dari banyak denyut peristiwa yang secara internal terhubung satu sama lain. Metafisika substansi juga menekankan suatu yang tetap dan tak berubah; perubahan yang ada hanyalah perubahan aksidental saja. Padahal realitas terus berubah. Yang ada (being) tak pernah dapat dimengerti lepas dari yang menjadi (becoming). "What a being is, is how it becomes." Sensasionalisme adalah pandangan bahwa pencerapan indrawi yang sudah terpilah-pilah merupakan cerapan realitas yang paling fundamental. Padahal pencerapan indrawi sudah merupakan abstraksi atas pengalawan awal kontak fisik langsung (causal efficacy) yang melibatkan seluruh kebertubuhan manusia; pengalaman awal kontak fisik langsung itu masih kabur karena belum terpilah-pilah, tetapi kaya dan kompleks serta mendasari persepsi indrawi kita.

Alam pikiran modern yang dualistik telah membuat manusia terasing dari alam dan pengembangkan kebudayaan yang tak lagi berangkat dari alam dan juga tidak berakar padanya. Manusia menjadi lupa bahwa dirinya merupakan bagian dari alam. Ia berhadapan dan berinteraksi dengan alam sebagai subjek terhadap objek, suatu barang mati untuk dikuasai dan dieksploitasi demi memenuhi kebutuhan manusia. Materialisme ilmiah juga mereduksi realitas pada apa yang dapat diamati, diukur dan 
dihitung. Unsur nilai-nilai, baik nilai intrinsik alam maupun nilai-nilai kemanusiaan cenderung diabaikan. Nilai intrinsik alam dianggap tidak ada karena alam dipandang sebagai barang mati yang hanya bernilai kalau manusia secara instrumental menggunakannya sedangkan nilainilai kemanusiaan, baik itu nilai estetis, etis maupun religius, dianggap sebagai suatu yang melulu subjektif karena tak dapat dibuktikan secara ilmiah. Karena yang diutamakan adalah pengetahuan yang secara pragmatis-utilitarian dapat digunakan untuk menguasai dan memanfaatkan alam, sisi keterlibatan subjek dengan perspektif nilai dalam mengalami dan memahami apa yang dialami lalu juga kurang mendapat tempat. Dengan kata lain, tidak ada ruang untuk hermeneutika budaya. Paham pemikiran itu kendati efektif secara pragmatis dan teknologis, tetapi telah menjadikan alam yang sesunguhnya hidup dan dinamis menjadi alam yang mati. Pendekatan mekanistik dan materialistik terhadap alam juga telah menyebabkan sikap eksploitatif terhadap alam menjadi merajalela. Perkembangan sains dan teknologi lepas dari kendali dan arahan nilainilai kemanusiaan. Sebagai akibatnya, kerusakan ekologis menjadi tak terhindarkan.

\section{Alternatif yang Ditawarkan}

Alternatif yang ditawarkan Whitehead adalah pandangan dunia berupa filsafat proses-relasional atau ia sendiri menyebutnya Filsafat Organisme. Dalam pandangan itu alam semesta dipahami sebagai suatu kesatuan rumah tinggal bersama (oikos) yang terdiri dari banyak unsur yang secara individual memiliki keunikan dan kemutlakan, tetapi secara internal terhubung dengan unsur-unsur yang lain bagaikan organismeorganisme mikroskopik dalam organisme yang lebih besar yang bersifat makroskopik. Di dalamnya kategori proses merupakan kategori yang dominan. Menurut Whitehead ada dua jenis proses, yakni proses yang ia sebut concrescence dan proses transition. Proses concrescence adalah proses pembentukan diri dengan secara fisik mengintegrasikan warisan masa lalu berupa objektivikasi entitas-entitas aktual sebelumnya dan secara mental mengintegrasikan cita-cita diri yang ditarik dari kemungkinankemungkinan yang sudah dipikirkan oleh Tuhan dalam kodrat awalnya 
(the primordial nature of God), sedangkan proses transition adalah objektivikasi diri pada yang lain dan pada keseluruhan. Proses objektivikasi yang terjadi dalam proses transition itu apa yang sudah terwujud tak akan hilang dan sia-sia karena mendapatkan imortalitas objektif dalam kodrat akhir (the consequent nature of God). Setiap bentuk perwujudan diri begitu mencapai kepenuhannya tidak akan berhenti di situ, tetapi menjadi prinsip pembentuk untuk munculnya entitas aktual yang baru. Kedua jenis proses itu menandai baik proses individual tiap entitas aktual, maupun proses masyarakat sebagai suatu kesatuan dan proses kosmologis secara keseluruhan.

\section{PENUTUP}

Sebagai semacam kesimpulan dari kajian kita dalam mengulik pemikiran Whitehead tentang kebudayaan, menurut pendapat penulis, ada beberapa butir gagasan yang kiranya dapat kita tarik bagi pengembangan budaya masyarakat dewasa ini. Butir-butir itu adalah sebagai berikut.

Pertama, seluruh kegiatan pengembangan budaya semestinya diarahkan untuk mewujudkan masyarakat yang berkeadaban, yakni masyarakat yang ditandai oleh lima nilai sebagaimana dikemukakan Whitehead, yakni Kebenaran, Keindahan, Seni, Petualangan dan Kedamaian. Kelimanya merupakan nilai-nilai yang menjadi kerangka cita-cita budaya yang mau diwujudkan bersama dalam masyarakat.

Kedua, seni-yang oleh Whitehead dipahami sebagai alat analisis dan konsep kunci dalam teorinya tentang peradaban-menjadi model utama dalam kegiatan pegembangan kebudayaan dalam masyarakat. Semua kegiatan pengembangan kebudayaan perlu dilakukan sebagai upaya menampakkan keindahan yang benar, keindahan yang menghormati keutuhan alam. Seni yang oleh Whitehead disebut "education of nature" perlu disesuaikan dengan alam dan berakakar di dalamnya. Aspek keindahan memang akan ditingkatkan oleh hadirnya unsur spontanitas dan petualangan imaginasi kreatif. Kedua unsur tersebut, yakni keindahan 
karya seni dan sifat artifisial seni memang penting untuk peradaban. Kesadaran manusia dan imaginasi kreatifnya dapat memperkaya unsur kontras dalam seni dan meningkatkan intensitas pengalaman. Namun bagi Whitehead, keindahan yang benar mengandaikan ketertanaman dalam kenyataan. Keindahan karya seni yang membawa ketercerabutan dari kenyataan hanya akan membawa nada sumbang dan kekacauan.

Ketiga, kendati keselarasan sosial masyarakat dalam masyarakat yang berkeadaban layak dicita-citakan, pengembangan kebudayaan perlu terus memberi ruang bagi petualangan gagasan dan kebebasan individu untuk mengembangkan imaginasi kreatifnya. Tidak ada capaian budaya yang menjadi puncak-puncak kebudayaan yang tak perlu diperbarui lagi. Pengulangan terus menerus produk budaya yang dianggap sempurna tanpa modifikasi dan pembaruan, hanya akan membawa ke kejenuhan dan hilangnya vitalitas kehidupan.

Keempat, sains, teknologi, etika, agama, dan filsafat adalah bentukbentuk kepentingan budaya lewat mana cita-cita budaya di atas mau diwujudkan. Sains secara khusus menunjang kegiatan budaya yang mau mewujudkan nilai Kebenaran dan Petualangan. Sementara itu, agama, kendati perlu memberi ruang bagi unsur Petualangan dengan memberi ruang penyesuaian dengan perubahan zaman, pertama-tama perlu mengupayakan terwujudnya rasa Kedamaian dalam hati setiap warga masyarakat. Kegiatan budaya dalam masyarakat perlu dapat mengintegrasikan dalam diri manusia beragama perspektif transenden/ilahi maupun imanen/duniawi.

Kelima, manusia sebagai pusat dan pelaku budaya adalah bagian dari alam; oleh karenanya, manusia perlu selalu berusaha agar kegiatan budaya dalam mengolah dan memelihara alam serta dalam berbagai upaya memenuhi kebutuhan hidupnya tidak mengasingkan dirinya dari alam.

\section{DAFTAR RUJUKAN}

Geertz, Clifford. The Interpretation of Cultures. New York: Basic Books, 1973. 
Griffin, David Ray. Whitehead's Radically Different Postmodern Philosophy: An Argument for Its Contemporary Relevance. Albany: State University of New York Press, 2007.

Hall, David L. The Civilization of Experience: A Whiteheadian Theory of Culture. New York: Fordham University Press, 1973.

Kroeber, A. L. and C. Kluckhohn. Culture: A Critical Review of Concepts and Definitions. Cambridge, MA: Harvard University Press, 1952.

Lunden, Lyman T. Risk and Rhetoric in Religion: Whitehead's Theory of Language and the Discourse of Faith. Philadelphia: Fortress Press, 1972.

Mesle, C. Robert. Process-Relational Philosophy: An Introduction to Alfred North Whitehead. West Conshohocken, PA: Templeton Foundation Press, 2008.

Whitehead, Alfred North. Adventures of Ideas. New York: The Free Press, (1933) 1967.

The Aim of Education and Other Essays. New York: The Free Press, (1929) 1967.

. "The First Physical Synthesis." In Interpretation of Science, Selected Essays. New York: The Bobbs-Merril Company, Inc., 1961. . Essays in Science and Philosophy. New York: The Philosophical Library, 1948.

. The Function of Reason. Boston: Beacon Press, (1929) 1958. . Modes of Thought. New York: The Free Press, (1938) 1968. . Process and Reality. New York: The Free Press, (1929) 1979. . Religion in the Making. New York: New Americn Library, (1926) 1974.

. Science and the Modern World. New York: The Free Press, (1926) 1967.

Symbolism, Its Meaning and Effect. New York: The Macmillan, Co., 1927. 